\title{
Rotational Spectrum and Structural Analysis of CH...F Interactions in the Vinyl Fluoride...1,1-Difluoroethylene Dimer
}

\author{
Rachel E. Dorris ${ }^{a}$, Sean A. Peebles ${ }^{a}$, Rebecca A. Peebles ${ }^{a} *$ \\ ${ }^{a}$ Department of Chemistry, Eastern Illinois University, 600 Lincoln Avenue, \\ Charleston, IL 61920, USA
}

*To whom correspondence should be addressed:

Email: rpeebles@eiu.edu

Phone: (217) 581-5906

(C) 2017. This manuscript version is made available under the Elsevier user license http://www.elsevier.com/open-access/userlicense/1.0/ 


\begin{abstract}
The structure of the weakly bound dimer of 1,1-difluoroethylene with vinyl fluoride was studied using Fourier-transform microwave spectroscopy in the $6-19 \mathrm{GHz}$ range. In the observed dimer structure each monomer acts as both a weak bond donor and acceptor, giving a cyclic arrangement of $\mathrm{C}-\mathrm{H} . . \mathrm{F}$ contacts. The difluoroethylene $\mathrm{C}=\mathrm{C}$ bond is roughly perpendicular to the vinyl fluoride $\mathrm{C}=\mathrm{C}$ bond, forming the cross of a $\mathrm{T}$-shaped carbon atom framework, resembling the lowest energy structure predicted by MP2/6-311++G(2d,2p) calculations. Observed C-H...F distances are similar to those of vinyl fluoride and 1,1difluoroethylene complexes with difluoromethane and $\mathrm{HCCH}$. The dipole moment of the dimer was measured using the Stark effect, giving values of $\mu_{a}=0.9003(19) \mathrm{D}, \mu_{b}=0.030(8) \mathrm{D}$ and $\mu_{\text {total }}=0.9008(22) \mathrm{D}$. A second ab initio structure, with the $\mathrm{C}=\mathrm{C}$ bonds in a slipped parallel arrangement, was predicted to be about $38 \mathrm{~cm}^{-1}$ higher in energy than the T-shaped conformation. This higher energy arrangement has not been observed experimentally.
\end{abstract}

Keywords: van der Waals complex, fluoroethene, 1,1-difluoroethene, dipole moment, Stark effect, weak hydrogen bond 


\section{Introduction}

Recently, we investigated dimers of vinyl fluoride (VF) with difluoromethane (DFM) and chlorofluoromethane (CFM) [1,2], and studies of the trifluoromethane (TFM)...VF complex are ongoing [3], although spectra are complicated by internal rotation in the latter case. Results from those studies could be combined with previous structural data on DFM complexed with 1,1difluoroethylene (DFE) and trifluoroethylene (TFE) [4] in order to gain insight into the nature of weak $\mathrm{CH}$...F interactions in these species and the variation of these interactions as the degree of fluorine substitution on the ethylene subunit was varied. It was found that in VF and TFE complexes DFM interacts with the H-C-F edge of VF (referred to as "side-bonded"), rather than along the $\mathrm{H}-\mathrm{C}=\mathrm{C}-\mathrm{F}$ edge (referred to as "top-bonded"). In order to maintain a cyclic type interaction with both $\mathrm{C}-\mathrm{H} \ldots \mathrm{F}$ and $\mathrm{C}-\mathrm{F}$...H contacts from the fluorinated ethylene to DFM, the arrangement of DFE...DFM is different, and DFM does lie along the top $\mathrm{H}-\mathrm{C}=\mathrm{C}-\mathrm{F}$ edge of 1,1DFE [4]. A summary of observed structures is given in Figures 2 and 3 of Reference [1].

A logical extension to these studies is to interactions of various fluoroethylenes with each other. VF dimer would likely be nonpolar, so our first step is investigation of the VF...1,1-DFE complex. We aim to answer three main questions via structural analysis of this dimer. First, is the minimum energy geometry planar, or will these two molecules adopt a nonplanar arrangement, perhaps with a weak C-H... $\pi$ contact, as has been observed in acetylene complexes with fluorinated methanes $[5,6,7,8]$ ? Second, if the structure is planar, will DFE interact with the H-C-F side of VF, as has been observed in complexes of DFM and CFM with VF? Finally, how do the strength and orientations of observed C-H...F contacts compare to those in related species? 


\section{Experimental Methods}

The sample mixture was prepared in a steel tank and consisted of about $1 \%$ VF $(98 \%$ Synquest Laboratories) and 1\% DFE (Synquest Laboratories) diluted in first-run helium-neon (BOC Gases; $82.5 \% \mathrm{Ne}, 17.5 \% \mathrm{He}$ ) and delivered to a General Valve Series 9 pulsed nozzle with $0.8 \mathrm{~mm}$ orifice at $2-2.5 \mathrm{~atm}$ backing pressure. The spectrum was scanned using the reduced $(480 \mathrm{MHz})$ bandwidth chirped-pulse (CP) Fourier-transform microwave (FTMW) spectrometer at Eastern Illinois University (EIU) [9]. Individual $480 \mathrm{MHz}$ spectra recorded with each center frequency separated by $240 \mathrm{MHz}$ from the previous step across the $7.5-19 \mathrm{GHz}$ range, were compiled into a single broadband spectrum using a LabVIEW routine. At each center frequency, 2000 Fourier-transformed spectra were averaged, and the LabVIEW routine also compared overlapping spectra to translate offsets from each center frequency into absolute transition frequencies. Following initial assignment of the spectrum, additional measurements (for Stark effects, ${ }^{13} \mathrm{C}$ isotopologues, and weaker transitions of the most abundant isotopologue) were performed using the resonant cavity(RC) FTMW spectrometer at EIU $[10,11]$.

Stark effect measurements were performed by applying voltages of up to $\pm 5 \mathrm{kV}$ to a pair of steel mesh plates separated by $\sim 31 \mathrm{~cm}$ and straddling the gas expansion and Fabry-Perot cavity of the RC-FTMW spectrometer. The electric field was calibrated using the $J=1-0$ transition of OCS, assuming a dipole moment of 0.71519(3) D [12].

\section{Results}

\section{A. Ab Initio Calculations}

Two planar structures for VF...DFE, both containing a pair of weak CH...F interactions, were optimized at the MP2/6-311++G(2d,2p) level using Gaussian 03 (Figure 1) [13]. Tight 
SCF convergence criteria and MP2 densities for properties were used. In the resulting structures, the slipped parallel orientation (Fig. 1(b), structure II) of double bonds was about $38 \mathrm{~cm}^{-1}$ less stable than the perpendicular double bond orientation (Fig. 1(a), structure I) at the zero point energy and basis set superposition error uncorrected level (Table 1). Since optimizations did not strictly enforce symmetry, optimized configurations are not quite planar, giving small values for out of plane dipole moment components $\left(\mu_{c} \sim 0.01 \mathrm{D}\right.$ and $\left.0.02 \mathrm{D}\right)$ and planar moments $\left(P_{c c} \sim\right.$ $0.002 \mathrm{u} \AA^{2}$ and $0.007 \mathrm{u} \AA^{2}$ ), respectively, for structures I and II. The $\mu_{b}$ dipole components are also predicted to be very small (less than $0.1 \mathrm{D}$ ) for both orientations of the dimer as a result of the monomers aligning such that one component of the VF dipole moment (experimental values: $\left.\mu_{a}=1.284(4) \mathrm{D}, \mu_{b}=0.712(12) \mathrm{D}, \mu_{\text {total }}=1.468(7) \mathrm{D}[14]\right)$ opposes the dipole moment of DFE (experimental value: $\mu_{a}=1.3893(14) \mathrm{D}$ [15]). Principal axis coordinates for both structures I and II are given in Supplementary Materials. Attempts to locate stationary points corresponding to any nonplanar structures were unsuccessful.

(a)

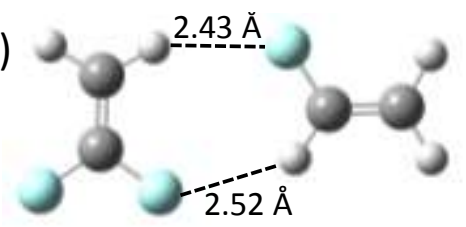

Structure I

$\Delta E=0 \mathrm{~cm}^{-1}$

(b)

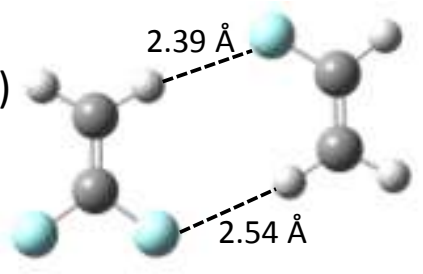

Structure II

$\Delta E=38 \mathrm{~cm}^{-1}$

Figure 1. MP2/6-311++G(2d,2p) structures for the vinyl fluoride...1,1difluoroethylene dimer, (a) Structure I, (b) Structure II. $\Delta E$ is the relative energy (zero point energy and basis set superposition error uncorrected). 
For the purposes of prediction and assignment of observed spectra, $B$ and $C$ for both structures I and II are very similar and are not sufficiently different to distinguish between the two possible configurations based only on these values; however, $A$ is significantly different for the two structures, even accounting for expected higher uncertainty in experimental values of $A$ for $a$-type spectra. In addition, predicted $P_{b b}$ planar moments are quite different for structures I and II, as are $\mu_{a}$ dipole components, and these should help confirm which ab initio structure corresponds most closely to the experimental result.

Table 1. Ab initio (MP2/6-311++G(2d,2p)) parameters for structures I and II, shown in Figure 1. Structure I Structure II

\begin{tabular}{lrr}
\hline$A / \mathrm{MHz}$ & 6627.9 & 5284.6 \\
$B / \mathrm{MHz}$ & 837.9 & 884.8 \\
$C / \mathrm{MHz}$ & 743.8 & 757.9 \\
$P_{a a} / \mathrm{u} \AA^{2 a}$ & 603.2 & 571.2 \\
$P_{b b} / \mathrm{u} \AA^{2 a}$ & 76.2 & 95.6 \\
$P_{c c} / \mathrm{u} \AA^{2 a}$ & 0.002 & 0.007 \\
$\mu_{a} / \mathrm{D}$ & 0.84 & 1.60 \\
$\mu_{b} / \mathrm{D}$ & 0.10 & 0.04 \\
$\mu_{c} / \mathrm{D}$ & 0.01 & 0.02 \\
$\mu_{\mathrm{total}} / \mathrm{D}^{2}$ & 0.85 & 1.60 \\
$E / E_{\mathrm{h}}$ & -454.046056 & -454.045885 \\
$E_{B} / \mathrm{kJ} \mathrm{mol}^{-1 b}$ & 9.6 & 9.1 \\
$\Delta E / \mathrm{cm}^{-1} c$ & 0.0 & 38.0
\end{tabular}

${ }^{a}$ Planar moments, $P_{a a}=\overline{1 / 2\left(I_{b}+I_{c}-I_{a}\right)=\Sigma m_{i} a_{i}^{2} \text {, with permutations for } P_{b b}}$ and $P_{c c}$.

${ }^{b}$ Binding energy of dimer without basis set superposition error correction, $E_{B}=\mid E_{\mathrm{dimer}}-E_{\mathrm{VF}}-$ $E_{\mathrm{DFE}}$, where monomers were optimized independently of the dimer.

${ }^{c}$ Relative energies calculated at the zero point energy and basis set superposition error uncorrected level. 
For later comparison with our approximate experimental values (section IV, below), the binding energies for both dimer structures were estimated using MP2/6-311++G(2d,2p) calculations by taking the difference between each dimer's absolute energy and the sum of the energies of the separate monomers. If separately optimized monomer structures are used for this, the binding energies of $\sim 9 \mathrm{~kJ} \mathrm{~mol}^{-1}$ reported in Table 1 are obtained, with Structure I more strongly bound by $0.5 \mathrm{~kJ} \mathrm{~mol}^{-1}$. More sophisticated calculations incorporating monomer relaxation and basis set superposition error corrections might give more accurate binding energies, but these are beyond the scope of the present work, and the difference between the two structures is not expected to change significantly.

\section{B. Spectra}

The spectrum of VF...DFE was scanned using the EIU CP-FTMW spectrometer in the $7.5-19 \mathrm{GHz}$ range, although loss of sensitivity above about $16 \mathrm{GHz}$ prevented assignment of transitions at the high end of the frequency range. A series of $K_{a}=0$ and $K_{a}=1$ transitions with $J^{\prime}$ ranging from 5 to 7 was identified very close to the ab initio prediction for structure I. Initial assignments and pattern matching utilized Kisiel's AABS suite of programs [16], interfaced with Pickett's SPFIT/SPCAT package [17]. These were fitted to a Watson A-reduction Hamiltonian in the $I^{\mathrm{r}}$ representation [18]. After additional transitions were measured using the more sensitive RC-FTMW spectrometer, a final fit of 37 -type transitions with an RMS deviation of $0.97 \mathrm{kHz}$ was obtained. Fitted transition frequencies are listed in Table 2, and resulting constants are given in Table 3. Although the dimer is very near prolate $(\kappa \sim-0.97)$, an $S$ reduction fit gave identical results. The predicted very small $\mu_{b}$ dipole component meant that $b$-type transitions could not be observed, and this led to a higher than usual uncertainty in the $A$ rotational constant, 
since $a$-type transition frequencies for near-prolate tops depend mainly on $B$ and $C$. The fitted $\Delta_{K}$ value of $-2.90(3) \mathrm{MHz}$ is much larger than would be expected for a molecule of this type. The correlation between $A$ and $\Delta_{K}$ in the least-squares fit of SPFIT is $\sim-0.93$, and this relatively high correlation likely contributes to the high $\Delta_{K}$ value. In addition, the $P_{c c}$ planar moment should be zero for a planar molecule. Often, observed $P_{c c}$ values of planar dimers are a few tenths of a $\mathrm{u} \AA^{2}$. The larger observed value $\left(\sim 1.9 \mathrm{u} \AA^{2}\right)$ for VF...DFE is an indication of possible significant floppiness in the dimer, which would also be consistent with the large observed $\Delta_{K}$ value.

Quite a few unassigned transitions remain in the original broadband scan, but attempts at assignment to a higher energy configuration such as structure II have so far been fruitless. Although the two ab initio conformers are predicted to be relatively close in energy, we have previously only observed a second dimer structure when the predicted energy difference was considerably smaller (under $10 \mathrm{~cm}^{-1}$ ) [19]. Also, the difference could increase with application of zero point energy and/or basis set superposition error corrections, making it less likely that the second configuration would be observed experimentally. Transitions of the higher energy conformer may also lie in frequency ranges that contain weak transitions from other species, making pattern matching more difficult. Other unassigned species whose spectra could be present are polar conformations of the homo-dimers of VF or DFE, water complexes of either species, or neon complexes of VF (Ne...1,1-DFE has previously been studied and could be eliminated from our scans [20]). 
Table 2. Measured transition frequencies for vinyl fluoride...1,1-difluoroethylene complex.

\begin{tabular}{|c|c|c|c|c|c|c|c|}
\hline$J^{\prime}$ & $K_{a}^{\prime}$ & $K_{c}{ }^{\prime}$ & $J^{\prime \prime}$ & $K_{a}^{\prime \prime}$ & $K_{c}^{\prime \prime}$ & $v_{\mathrm{obs}} / \mathrm{MHz}$ & $v_{\text {obs }}-v_{\text {calc }} / \mathrm{MHz}$ \\
\hline 4 & 1 & 4 & 3 & 1 & 3 & 6128.4651 & 0.0015 \\
\hline 4 & 2 & 3 & 3 & 2 & 2 & 6308.0444 & -0.0028 \\
\hline 4 & 2 & 2 & 3 & 2 & 1 & 6318.3092 & -0.0007 \\
\hline 4 & 1 & 3 & 3 & 1 & 2 & 6485.6424 & 0.0001 \\
\hline 5 & 1 & 5 & 4 & 1 & 4 & 7658.5539 & -0.0001 \\
\hline 5 & 0 & 5 & 4 & 0 & 4 & 7865.8217 & -0.0001 \\
\hline 5 & 2 & 4 & 4 & 2 & 3 & 7883.6217 & -0.0002 \\
\hline 5 & 3 & 3 & 4 & 3 & 2 & 7888.7963 & -0.0001 \\
\hline 5 & 3 & 2 & 4 & 3 & 1 & 7888.9509 & 0.0004 \\
\hline 5 & 2 & 3 & 4 & 2 & 2 & 7904.1218 & 0.0003 \\
\hline 5 & 1 & 4 & 4 & 1 & 3 & 8104.9103 & -0.0004 \\
\hline 6 & 1 & 6 & 5 & 1 & 5 & 9187.3333 & -0.0005 \\
\hline 6 & 0 & 6 & 5 & 0 & 5 & 9427.5504 & 0.0000 \\
\hline 6 & 2 & 5 & 5 & 2 & 4 & 9458.2384 & -0.0004 \\
\hline 6 & 3 & 4 & 5 & 3 & 3 & 9467.6274 & -0.0008 \\
\hline 6 & 3 & 3 & 5 & 3 & 2 & 9468.0389 & 0.0000 \\
\hline 6 & 2 & 4 & 5 & 2 & 3 & 9494.0337 & 0.0006 \\
\hline 6 & 1 & 5 & 5 & 1 & 4 & 9722.7115 & 0.0010 \\
\hline 7 & 1 & 7 & 6 & 1 & 6 & 10714.5802 & -0.0002 \\
\hline 7 & 0 & 7 & 6 & 0 & 6 & 10983.1712 & -0.0003 \\
\hline 7 & 2 & 6 & 6 & 2 & 5 & 11031.7072 & -0.0001 \\
\hline 7 & 3 & 5 & 6 & 3 & 4 & 11046.9789 & -0.0007 \\
\hline 7 & 3 & 4 & 6 & 3 & 3 & 11047.9047 & 0.0015 \\
\hline 7 & 2 & 5 & 6 & 2 & 4 & 11088.7698 & -0.0007 \\
\hline 7 & 1 & 6 & 6 & 1 & 5 & 11338.7085 & 0.0017 \\
\hline 8 & 1 & 8 & 7 & 1 & 7 & 12240.0928 & 0.0011 \\
\hline 8 & 0 & 8 & 7 & 0 & 7 & 12531.8409 & -0.0001 \\
\hline 8 & 2 & 7 & 7 & 2 & 6 & 12603.8386 & 0.0014 \\
\hline 8 & 3 & 6 & 7 & 3 & 5 & 12626.8824 & -0.0016 \\
\hline
\end{tabular}




\begin{tabular}{cccccccc}
\hline 8 & 3 & 5 & 7 & 3 & 4 & 12628.7319 & 0.0023 \\
8 & 2 & 6 & 7 & 2 & 5 & 12688.9617 & -0.0010 \\
8 & 1 & 7 & 7 & 1 & 6 & 12952.5417 & -0.0007 \\
9 & 1 & 9 & 8 & 1 & 8 & 13763.6894 & 0.0004 \\
9 & 2 & 8 & 8 & 2 & 7 & 14174.4384 & -0.0010 \\
9 & 2 & 7 & 8 & 2 & 6 & 14295.0952 & -0.0002 \\
9 & 1 & 8 & 8 & 1 & 7 & 14563.8340 & 0.0004 \\
10 & 0 & 10 & 9 & 0 & 9 & 15605.7119 & -0.0007 \\
\hline
\end{tabular}

Following assignment of the most abundant isotopologue, spectra of all four unique ${ }^{13} \mathrm{C}$ substituted species were assigned in natural abundance ( 1\%) using the RC-FTMW spectrometer. Because of the significantly lower transition intensity, data sets were limited to 910 lines each, and all distortion constants except $\Delta_{J}$ were fixed to values from the parent species. Fitted constants for isotopic species are included in Table 3, while ${ }^{13} \mathrm{C}$ transition frequencies are included in Supplementary Materials.

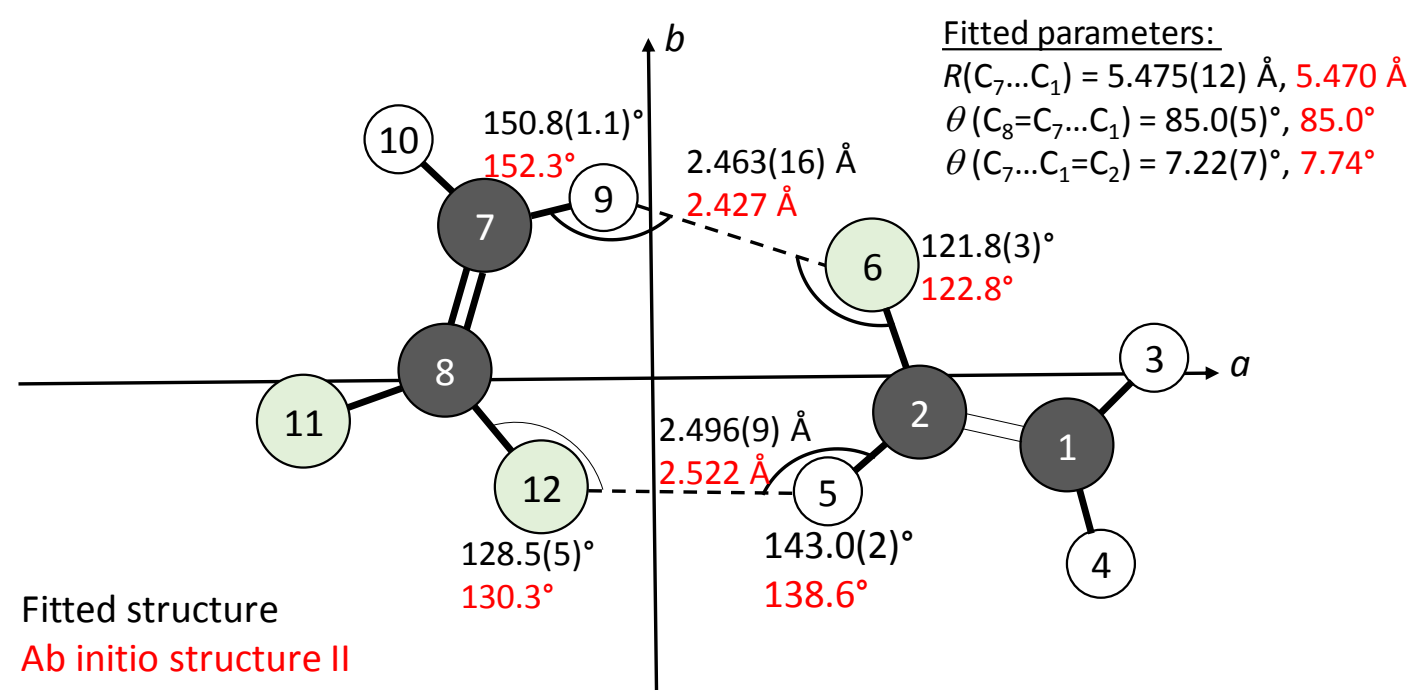

Figure 2. Fitted (black) and ab initio (red) structures for vinyl fluoride...1,1-difluoroethylene. 
Table 3. Fitted constants for normal and ${ }^{13} \mathrm{C}$ isotopologues of vinyl fluoride...1,1difluoroethylene. Constants for ab initio structure I and II are included for comparison in the last two columns. See Figure 2 for atom numbers of ${ }^{13} \mathrm{C}$ isotopologues.

\begin{tabular}{llllllll}
\hline & Normal & ${ }^{13} \mathrm{C}_{1}$ & ${ }^{13} \mathrm{C}_{2}$ & ${ }^{13} \mathrm{C}_{7}$ & ${ }^{13} \mathrm{C}_{8}$ & $\mathrm{I}$ & $\mathrm{II}$ \\
\hline$A / \mathrm{MHz}$ & $6601.14(9)$ & $6565.7(5)$ & $6590.7(10)$ & $6448.4(7)$ & $6603.4(7)$ & 6627.9 & 5284.6 \\
$B / \mathrm{MHz}$ & $833.33356(13)$ & $815.5574(4)$ & $825.6952(6)$ & $830.4284(6)$ & $828.8043(5)$ & 837.9 & 884.8 \\
$C / \mathrm{MHz}$ & $744.02168(12)$ & $729.4334(4)$ & $737.8283(6)$ & $739.7553(5)$ & $740.4071(7)$ & 743.8 & 757.9 \\
$\Delta_{J} / \mathrm{kHz}$ & $0.90880(53)$ & $0.8557(46)$ & $0.9110(59)$ & $0.8932(88)$ & $0.9247(70)$ & & \\
$\Delta_{J K} / \mathrm{kHz}$ & $10.891(5)$ & {$[10.891]^{a}$} & {$[10.891]$} & {$[10.891]$} & {$[10.891]$} & & \\
$\Delta_{K} / \mathrm{MHz}$ & $-2.90(3)$ & {$[-2.90]$} & {$[-2.90]$} & {$[-2.90]$} & {$[-2.90]$} & & \\
$\delta_{J} / \mathrm{kHz}$ & $0.0485(5)$ & {$[0.0485]$} & {$[0.0485]$} & {$[0.0485]$} & {$[0.0485]$} & & \\
$P_{a a} / \mathrm{u} \AA^{2 b}$ & $604.5742(7)$ & $617.769(3)$ & $610.1695(11)$ & $606.687(5)$ & $607.903(5)$ & 603.2 & 571.2 \\
$P_{b b} / \mathrm{u} \AA^{2 b}$ & $74.6789(7)$ & $75.069(3)$ & $74.7852(11)$ & $76.484(5)$ & $74.667(5)$ & 76.2 & 95.6 \\
$P_{c c} / \mathrm{u} \AA^{2 b}$ & $1.8805(7)$ & $1.904(3)$ & $1.8954(11)$ & $1.889(5)$ & $1.866(5)$ & 0.002 & 0.007 \\
$N^{c}$ & 38 & 10 & 10 & 9 & 9 & & \\
$\mathrm{rms} / \mathrm{kHz}{ }^{d}$ & 0.97 & 2.4 & 3.9 & 3.1 & 3.4 & & \\
\hline
\end{tabular}

${ }^{a}$ Constants in [] fixed to value from normal isotopologue.

${ }^{b}$ Planar moments, $P_{a a}=1 / 2\left(I_{b}+I_{c}-I_{a}\right)=\Sigma m_{i} a_{i}^{2}$, with permutations for $P_{b b}$ and $P_{c c}$.

${ }^{c}$ Number of transitions fitted

${ }^{d}$ Root-mean-square deviation of observed frequencies: $\left[\frac{\Sigma\left(v_{o b s}-v_{\text {calc }}\right)^{2}}{N}\right]^{1 / 2}$.

\section{Dipole moment}

A total of 45 individual Stark effect measurements (from 8 components of 5 rotational transitions) were fitted using the QSTARK program [21], with a standard deviation of $5.2 \mathrm{kHz}$. Rotational and centrifugal distortion constants were fixed at the values in Table 3 . Resulting dipole moment components were $\mu_{a}=0.9003(19) \mathrm{D}, \mu_{b}=0.030(8) \mathrm{D}$ and $\mu_{\text {total }}=0.9008(22) \mathrm{D}$. Best fits were obtained when $\mu_{c}$ was constrained to be zero. Details of individual measurements are included in Supplementary Material. Ab initio dipole moment components for structure I agree well with experimental values, although $\mu_{a}$ was slightly underestimated by about $0.06 \mathrm{D}$, and $\mu_{b}$ was overestimated by a similar amount (Table 1 ). 
Projection of experimental monomer dipole moment components (VF: $\mu_{a}=1.284(4) \mathrm{D}$, $\mu_{b}=0.712$ (12) D [14]; 1,1-DFE: $\mu_{a}=1.3893(14) \mathrm{D}$ [15]) onto principal axes of the fitted dimer structure (see Section D, below) gives $\mu_{a}=0.80 \mathrm{D}, \mu_{b}=0.07 \mathrm{D}$ and $\mu_{\text {total }}=0.80 \mathrm{D}$, indicating an induced dipole of about $0.1 \mathrm{D}$ along the $a$ axis, which corresponds roughly to the direction of the two intermolecular C-H...F contacts. Looking at the relative alignment of the two monomers, it is clear that the positive direction of the $\mu_{a}$ dipole component of the dimer is in the positive $a$ direction (Figure 2). The small enhancement compared to projections of monomer dipoles may indicate greater transfer of electron density from VF towards 1,1-DFE in the $\mathrm{F}_{6} \ldots \mathrm{H}_{9}-\mathrm{C}_{7}$ contact than there is from 1,1-DFE towards VF in the $\mathrm{F}_{12} \ldots \mathrm{H}_{5}-\mathrm{C}_{2}$ contact. This would be consistent with the hydrogen atoms in 1,1-DFE being more acidic than those in VF, which follows the trend of increasing acidity as degree of fluorine substitution is increased [22].

\section{Structure}

Experimental rotational constants were all within $\sim 0.5 \%$ of ab initio values for structure I. Although $B$ and $C$ are similar for both structures, both the observed rotational constants and planar moments were much closer to the predicted values for structure I than structure II. A planar geometry was confirmed by the small $P_{c c}$ planar moments $\left(P_{c c}=0.5\left(I_{a}+I_{b}-I_{c}\right)=\Sigma m_{i} c_{i}^{2}\right)$ for all assigned isotopologues (Table 3), although for a rigid planar structure $P_{c c}$ would be expected to be zero, and the observed small values $\left(\sim 1.8-1.9 \mathrm{u} \AA^{2}\right)$ indicate some out-of-plane floppiness in the relatively elongated structure. Assuming a planar geometry, three intermolecular parameters are needed to uniquely define the structure of the dimer, with the assumption that monomers are constrained to literature structures (Table 4) [23,24]. 
Table 4. Literature structures of vinyl fluoride [23] and 1,1-difluoroethylene [24] monomers used for least-squares fits of the dimer structure. Atom numbers refer to Figure 2.

\begin{tabular}{llll}
\hline$\underline{\mathrm{C}}_{2} \underline{\mathrm{H}}_{3} \underline{\mathrm{F}}$ & \multicolumn{3}{c}{$\underline{\mathrm{C}}_{2} \underline{\mathrm{H}}_{2} \underline{\mathrm{F}}_{2}$} \\
\hline$R\left(\mathrm{C}_{1}-\mathrm{H}_{3}\right) / \AA$ & 1.087 & $R\left(\mathrm{C}_{7}-\mathrm{H}_{9,10}\right) / \AA$ & 1.079 \\
$R\left(\mathrm{C}_{1}-\mathrm{H}_{4}\right) / \AA$ & 1.077 & & \\
$R\left(\mathrm{C}_{2}-\mathrm{H}_{5}\right) / \AA$ & 1.082 & & \\
$R\left(\mathrm{C}_{2}-\mathrm{F}_{6}\right) / \AA$ & 1.347 & $R\left(\mathrm{C}_{8}-\mathrm{F}_{11,12}\right) / \AA$ & 1.323 \\
$R\left(\mathrm{C}_{1}=\mathrm{C}_{2}\right) / \AA$ & 1.329 & $R\left(\mathrm{C}_{7}=\mathrm{C}_{8}\right) / \AA$ & 1.315 \\
$\theta\left(\mathrm{H}_{3}-\mathrm{C}_{1}=\mathrm{C}_{2}\right) / \circ$ & 120.9 & $\theta\left(\mathrm{H}_{9,10}-\mathrm{C}_{7}=\mathrm{C}_{8}\right) / \circ$ & 119.1 \\
$\theta\left(\mathrm{H}_{4}-\mathrm{C}_{1}=\mathrm{C}_{2}\right) / \circ$ & 119.0 & & \\
$\theta\left(\mathrm{H}_{5}-\mathrm{C}_{2}=\mathrm{C}_{1}\right) / \circ$ & 129.2 & & \\
$\theta\left(\mathrm{F}_{6}-\mathrm{C}_{2}=\mathrm{C}_{1}\right) / \circ$ & 120.8 & $\theta\left(\mathrm{F}_{11,12}-\mathrm{C}_{8}=\mathrm{C}_{7}\right) / \circ$ & 125.5 \\
\hline
\end{tabular}

Least-squares fits of several different combinations of structural parameters (defining the structure through either C...C or F...H distances) to the moments of inertia or planar moments of the dimer (including all isotopic data) were attempted, using both STRFITQ [25] and STRFIT [26] programs. All structural definitions and both fitting programs gave equivalent results, and structural information reported here (Table 5) resulted from fits of the $\mathrm{C}_{1} \ldots \mathrm{C}_{7}$ distance and $\mathrm{C}_{2}=\mathrm{C}_{1} \ldots \mathrm{C}_{7}$ and $\mathrm{C}_{1} \ldots \mathrm{C}_{7}=\mathrm{C}_{8}$ angles using STRFIT (see Figure 2 for atom numbers). Since only two moments of inertia are independent for planar species (because $I_{a}+I_{b}=I_{c}$ ), fits were attempted using all three possible pairs of moments of inertia. Despite the larger than normal uncertainty in the $A$ rotational constant (Table 3 ), fits of structural parameters using $I_{a}$ and $I_{b}$ resulted in the lowest standard deviations (Table 5). Fits using $I_{b}$ and $I_{c}$ (eliminating the more uncertain $I_{a}$ values) led to parameters with significantly higher uncertainties and which were inconsistent with values obtained using $I_{a}$ and $I_{b}$ or $I_{a}$ and $I_{c}$. Fitting planar moments instead of moments of inertia did not provide any improvement in the precision of fitted structural parameters or the overall standard deviation of the fit. Attempts to fit a dihedral angle, allowing 
the structure to become nonplanar, were also unsuccessful. Principal axis coordinates of the preferred structure resulting from least-squares fits to $I_{a}$ and $I_{b}$ are given in Supplementary Materials.

Table 5. Results of least-squares fits of the structure of vinyl fluoride...1,1-difluoroethylene. The fit of $I_{a}$ and $I_{b}$ is preferred. Atom numbers correspond to Figure 2. Columns labeled I and II correspond to $\mathrm{ab}$ initio results.

\begin{tabular}{|c|c|c|c|c|c|c|}
\hline & $I_{a}, I_{b}$ & $I_{a}, I_{c}$ & $I_{b}, I_{c}$ & $r_{\mathrm{s}}$ & I & II \\
\hline \multicolumn{7}{|l|}{ Fitted Parameters } \\
\hline$R\left(\mathrm{C}_{1} \ldots \mathrm{C}_{7}\right) / \AA$ & $5.475(14)$ & $5.465(12)$ & $5.535(45)$ & $5.483(2)$ & 5.47 & 4.40 \\
\hline$\theta\left(\mathrm{C}_{2}=\mathrm{C}_{1} \ldots \mathrm{C}_{7}\right) / \circ$ & $7.220(18)$ & $7.282(20)$ & $11.519(13)$ & $8.1(8)$ & 7.7 & 80.7 \\
\hline$\theta\left(\mathrm{C}_{1} \ldots \mathrm{C}_{7}=\mathrm{C}_{8}\right) / \circ$ & $85.0(5)$ & $84.8(5)$ & $84.3(1.7)$ & $83.7(3)$ & 85.0 & 82.4 \\
\hline \multicolumn{7}{|l|}{ Derived Parameters } \\
\hline$R\left(\mathrm{~F}_{6} \ldots \mathrm{H}_{9}\right) / \AA$ & $2.463(16)$ & $2.453(14)$ & $2.457(52)$ & & 2.43 & 2.39 \\
\hline$R\left(\mathrm{~F}_{12} \ldots \mathrm{H}_{5}\right) / \AA$ & $2.496(9)$ & $2.477(8)$ & $2.561(27)$ & & 2.52 & 2.54 \\
\hline $\mathrm{RMS} / \mathrm{u} \AA^{2}$ & 0.029 & 0.032 & 0.148 & & & \\
\hline
\end{tabular}

Availability of single ${ }^{13} \mathrm{C}$ isotopic data for all four carbon atoms also allowed determination of the carbon atom framework structure by using Kraitchman's equations for single isotopic substitution [27] as implemented in Kisiel's KRA and EVAL programs [28]. This provided principal axis coordinates of the carbon atoms (Table 6) that are in excellent agreement with results from the inertial fit of $I_{a}$ and $I_{b}$ (Table 5), with a maximum difference from $r_{0}$ coordinates of less than $0.03 \AA$ (in the small $b$ coordinate of $\mathrm{C}_{2}$ ). In addition, comparison of both $r_{0}$ and $r_{s}$ coordinates with ab initio structures I and II confirms that only structure I is consistent with experimental results (the $b$ coordinate of $\mathrm{C}_{2}$ is significantly different for the two $\mathrm{ab}$ initio structures and structure I is clearly in much better agreement with the experiment). 
Table 6. Comparison of carbon atom principal axis coordinates ( $\AA$ ) from best $r_{0}$ structure, $r_{\mathrm{s}}$ structure, and ab initio $r_{e}$ structures I and II. Atom numbers correspond to Figure 2.

\begin{tabular}{lllll|llll}
\hline & $a$ & & & & $b$ & & & \\
\hline & $r_{0}$ & $\left|r_{\mathrm{s}}\right|$ & $r_{e}(\mathrm{I})$ & $r_{e}(\mathrm{II})$ & $r_{0}$ & $\mid r_{\mathrm{s}}$ & $r_{e}(\mathrm{I})$ & $r_{e}(\mathrm{II})$ \\
\hline $\mathrm{C}_{1}$ & $-3.6479(4)$ & $3.6447(4)$ & -3.648 & -3.016 & $0.6442(7)$ & $0.6531(50)$ & 0.630 & 0.086 \\
$\mathrm{C}_{2}$ & $-2.3586(2)$ & $2.3751(6)$ & -2.360 & -2.428 & $0.3220(1)$ & $0.3511(175)$ & 0.323 & 1.273 \\
$\mathrm{C}_{7}$ & $1.4551(133)$ & $1.4583(10)$ & 1.453 & 1.149 & $-1.3404(38)$ & $1.3532(34)$ & -1.344 & -1.290 \\
$\mathrm{C}_{8}$ & $1.8234(13)$ & $1.8258(8)$ & 1.820 & 1.770 & $-0.0781(3)$ & $0.1636(273) i$ & -0.075 & -0.125 \\
\hline
\end{tabular}

\section{Discussion}

Since the dimer $a$ axis closely approximates the direction of intermolecular contact, and therefore the direction of intermolecular stretching vibration, the strength of the weak interaction between DFE and VF was estimated by calculating the binding energy and intermolecular force constant via equations (1) and (2), based on a Lennard-Jones potential: [29, 30]

$$
\begin{gathered}
k_{S}=\frac{16 \pi^{4}\left(\mu R_{c m}\right)^{2}\left[4 B^{4}+4 C^{4}-(B-C)^{2}(B+C)^{2}\right]}{h D_{J}} \\
E_{B}=\frac{1}{72} k_{s} R_{c m}^{2}
\end{gathered}
$$

This gave a force constant, $k_{s}=3.19(4) \mathrm{N} \mathrm{m}^{-1}$ and binding energy, $E_{B}=5.32(15) \mathrm{kJ} \mathrm{mol}^{-1}$, corresponding to an intermolecular stretching frequency of about $45.0(3) \mathrm{cm}^{-1}$. Both $k_{s}$ and $E_{B}$ are considerably smaller than for difluoromethane (DFM)...VF $\left(k_{s}=6.4(1) \mathrm{N} \mathrm{m}^{-1}, E_{B}=9.1(3) \mathrm{kJ}\right.$ $\left.\mathrm{mol}^{-1}\right)[1]$, DFM...DFE $\left(k_{s}=4.68 \mathrm{~N} \mathrm{~m}^{-1}, E_{B}=7.6 \mathrm{~kJ} \mathrm{~mol}^{-1}\right)$ [4], and DFM...TFE complexes $\left(k_{s}=\right.$ $4.09 \mathrm{~N} \mathrm{~m}^{-1}, E_{B}=6.3 \mathrm{~kJ} \mathrm{~mol}^{-1}$ ) [4], despite similar in-plane C-H...F distances in all four species. DFM complexes, however, involve three weak contacts (see Figures 2 and 3 of reference [1]), where one C-H...F interaction lies within the heavy atom plane of the dimer, and an additional two C-H..F or C-F...H contacts originating from DFM straddle the heavy atom plane; in the 
present VF...DFE complex, only two (in-plane) interactions are present, so direct comparison of weak interactions may need to be made with caution.

Previous studies of (planar) dimers of VF and DFE with HCCH [31,32] and HF [33,34] show that C-F...H distances in DFE complexes are longer than in VF complexes $(2.646(11) \AA$ vs. 2.441(4) $\AA$ for $\mathrm{HCCH}$ and 1.98833(44) $\AA$ vs. 1.892(14) $\AA$ for HF), consistent with the observation in the present complex of $\mathrm{a} \sim 0.033 \AA$ longer $\mathrm{C}-\mathrm{F} . . \mathrm{H}$ distance to the DFE fluorine atom than to the VF fluorine atom. Observed distances in VF...DFE (2.496(9) $\AA$ and 2.463(16) $\AA$ ) are very similar to the VF...HCCH distance of 2.441(4) $\AA$, while the acid, HF, forms stronger and much shorter hydrogen bonds. Although C-F...H angles in VF...DFE are likely to be constrained by the cyclic double C-H...F interactions present in the dimer, both angles $\left(128.5^{\circ}\right.$, $121.8^{\circ}$ ) are similar to those observed previously for complexes of VF and DFE with both HF and $\mathrm{HCCH}$, which have typically been $\sim 122^{\circ}[31,32,33,34]$.

\section{Conclusions}

Fourier-transform microwave spectroscopy has been used to study the weak complex formed between vinyl fluoride and 1,1-difluoroethylene. The dimer is planar and contains two weak C-H...F interactions, leading to a cyclic structure in which DFE forms the top of a T shaped arrangement of $\mathrm{C}=\mathrm{C}$ bonds. As with DFM...VF, DFE interacts with the H-C-F end of VF, rather than with the $\mathrm{H}$ and $\mathrm{F}$ atoms that are separated by two carbon atoms along the $\mathrm{H}$ $\mathrm{C}=\mathrm{C}-\mathrm{F}$ side. The estimated binding energy of the complex is less than for related species, which may be a result of many other $\mathrm{C}-\mathrm{H}$...F containing dimers having three weak contacts, compared to only two contacts in the present species. Weak C...H interaction distances are similar to other complexes of VF and DFE, and the previously observed trend of slightly longer C-H...F 
distances to the DFE fluorine atom than to the VF fluorine atom is also consistent with the present case.

\section{Acknowledgements}

This work was supported by National Science Foundation grants RUI CHE-0809387 and RUI CHE1214070. The authors thank Cori Christenholz for her contributions to the initial data collection and assignment. Finally, the authors would like to acknowledge the unselfish support and assistance that Professor Walther Caminati has provided to them and to the spectroscopic community. His advice and insight have contributed greatly to our research success over many years. 


\section{Reference}

[1] C.L. Christenholz, D.A. Obenchain, R.A. Peebles, S.A. Peebles, J. Phys. Chem. A 118 (2014) 1610-1616.

[2] C.L. Christenholz, D.A. Obenchain, S.A. Peebles, R.A. Peebles, J. Mol. Spectrosc. 280 (2012) 61-67.

[3] L.F. Elmuti, D.A. Obenchain, R.A. Peebles, S.A. Peebles, $67^{\text {th }}$ International Symposium on Molecular Spectroscopy, Columbus, OH, Talk MH07, June 18, 2012.

[4] Y. Tatamitani, K. Yamanou, H. Kanno, T. Ogata, J. Mol. Spectrosc. 242 (2007) 150-155.

[5] D.A. Obenchain, R.A. Peebles, S.A. Peebles, manuscript in preparation.

[6] L.F. Elmuti, R.A. Peebles, S.A. Peebles, A.L. Steber, J.L. Neill, B.H. Pate, Phys. Chem. Chem. Phys. 13 (2011) 14043-14049.

[7] J.M. Sexton, A.A. Elliott, A.L. Steber, S.A. Peebles, R.A. Peebles, J.L. Neill, M.T. Muckle, B.H. Pate, Phys. Chem. Chem. Phys. 12 (2010) 14263-14270.

[8] D.A. Obenchain, B.J. Bills, C.L. Christenholz, L.F. Elmuti, J.L. Neill, A.L. Steber, J. Phys. Chem. A 115 (2011) 12228-12234.

[9] D.A. Obenchain, A.A. Elliott, A.L. Steber, R.A. Peebles, S.A. Peebles, C.J. Wurrey, G.A. Guirgis, J.Mol. Spectrosc. 261 (2010) 35-40.

[10] T.J. Balle, W.H. Flygare, Rev. Sci. Instrum. 52 (1981) 33-45.

[11] J.J. Newby, M.M. Serafin, R.A. Peebles, S.A. Peebles, Phys. Chem. Chem. Phys. 7 (2005) 487-492.

[12] J.M.L.J. Reinartz, A. Dymanus, Chem. Phys. Lett. 24 (1974) 346-351.

[13] M.J. Frisch, G.W. Trucks, H.B. Schlegel, G.E. Scuseria, M.A. Robb, J.R. Cheeseman, J.A. Montgomery Jr., T. Vreven, K.N. Kudin, J.C. Burant, J.M. Millam, S.S. Iyengar, J. Tomasi, V. Barone, B. Mennucci, M. Cossi, G. Scalmani, N. Rega, G.A. Petersson, H. Nakatsuji, M. Hada, M. Ehara, K. Toyota, R. Fukuda, J. Hasegawa, M. Ishida, T. Nakajima, Y. Honda, O. Kitao, H. Nakai, M. Klene, X. Li, J.E. Knox, H.P. Hratchian, J.B. Cross, V. Bakken, C. Adamo, J. Jaramillo, R. Gomperts, R.E. Stratmann, O. Yazyev, A.J. Austin, R. Cammi, C. Pomelli, J.W. Ochterski, P.Y. Ayala, K. Morokuma, G.A. Voth, P. Salvador, J.J. Dannenberg, V.G.

Zakrzewski, S. Dapprich, A.D. Daniels, M.C. Strain, O. Farkas, D.K. Malick, A.D. Rabuck, K. Raghavachari, J.B. Foresman, J.V. Ortiz, Q. Cui, A.G. Baboul, S. Clifford, J. Cioslowski, B.B. Stefanov, G. Liu, A. Liashenko, P. Piskorz, I. Komaromi, R.L. Martin, D.J. Fox, T. Keith, M.A. Al-Laham, C.Y. Peng, A. Nanayakkara, M. Challacombe, P.M.W. Gill, B. Johnson, W. Chen, M.W. Wong, C. Gonzalez, J.A. Pople, Gaussian 03, Revision D.01, Gaussian, Inc., Wallingford, CT, 2004.

[14] M. Hayashi, T. Inagusa, J. Mol. Spectrosc. 138 (1989) 135-140.

[15] L.H. Johnston, H.C. Chou, S.R. Raju, G.R. Sudhakaran, M.C.L. Gerry, R. Wellington Davis, J. Mol. Spectrosc. 124 (1987) 317-332.

[16] Z. Kisiel, L. Pszczolkowski, I.R. Medvedev, M. Winnewisser, F.C. De Lucia, E. Herbst, J. Mol. Spectrosc. 233 (2005) 231-243.

[17] H.M. Pickett, J. Mol. Spectrosc. 148 (1991) 371-377.

[18] J.K.G. Watson, In Vibrational Spectra and Structure, J.R. Durig, Ed.; Elsevier: New York, (1977) Vol. 6.

[19] C.L. Christenholz, R.E. Dorris, R.A. Peebles, S.A. Peebles, J. Phys. Chem. A 118 (2014) 8765-8772. 
[20] A. Dell'Erba, S. Melandri, A. Millemaggi, W. Caminati, P.G. Favero, J. Chem. Phys. 112 (2000) 2204-2209.

[21] Z. Kisiel, J. Kosarzewski, B.A. Pietrewicz, L. Pszczolkowski, Chem. Phys. Lett. 325 (2000) 523-530.

[22] N.C. Craig, A.R. Matlin, J. Org. Chem. 79 (2014) 1729-1735.

[23] D.R. Lide Jr., D. Christensen, Spectrochim. Acta 17 (1961) 665-668.

[24] V.W. Laurie, D.T. Pence, J. Chem. Phys. 38 (1963) 2693.

[25] R.H. Schwendeman, in: D.R. Lide, M.A. Paul, (Eds.), Critical Evaluation of Chemical and Physical Structural Information, National Academy of Sciences, Washington, DC, 1974 (The STRFITQ program used in this work is the University of Michigan modified version of Schwendeman's original code).

[26] Z. Kisiel, J. Mol. Spectrosc. 218 (2003) 58-67.

[27] J. Kraitchman, Am. J. Phys. 21 (1953) 17-24.

[28] Kraitchman coordinates and structures from KRA and EVAL code, Z. Kisiel, PROSPE-Programs for Rotational Spectroscopy, http://www.ifpan.edu.pl/ kisiel/prospe.htm (accessed December 2016).

[29] D.J. Millen, Can. J. Chem. 63 (1985) 1477-1479.

[30] T.J. Balle, E.J. Campbell, M.R. Keenan, W.H. Flygare, J. Chem. Phys. 72 (1980) 922-932.

[31] G.C. Cole, A.C. Legon, Chem. Phys. Lett. 369 (2003) 31-40.

[32] H.O. Leung, M.D. Marshall, J. Chem. Phys. 125 (2006) 154301/1-8.

[33] G.C. Cole, A.C. Legon, Chem. Phys. Lett. 400 (2004) 419-424.

[34] H.O. Leung, M.D. Marshall, T.L. Drake, T. Pudlik, N. Savji, D.W. McCune, J. Chem. Phys. 131 (2009) 204301/1-8. 